\title{
On the trend of automobile repair market development in China
}

\author{
Xi JunHong, Zhu Liang \\ Yantai Vocational College, Shandong Yantai 264670
}

Keywords: Automobile repair market; Development trend

\begin{abstract}
Along with the economic development of China, now people's material life level has been effectively enhanced. The high-end consumption car in the past has entered ordinary families. In the process of people enjoying the convenience brought by cars, broad prospects also have been brought to corresponding automobile repair market. In this context, this paper first analyzes the market background, and then from several aspects studies our country automobile repair market development trend. The analysis can provide a certain direction for our country automobile repair market guidance and reference.
\end{abstract}

\section{Introduction}

After entering the 21st century, as a new developed automobile production and consumption power, our country's automobile service market faces both opportunities and challenges. Automobile repair market is an extremely important part of automobile service market. From the related data, if a car has $\$ 1$ consumption on the road, the corresponding related services will reach $\$ 8$. Foreign technology, capital, and the corresponding management concept and advanced production management have aggravated our country's automobile service market competition. In view of the current opportunities and challenges, in-depth analysis of the current development trend of automobile repair market in our country has particularly important practical significance to the development of related enterprise strategies.

\section{Analysis on the Background of Our Country'S Automobile Service Market}

A. Car ownership has maintained a sustained growth momentum.

Car ownership in China at the end of 2013, according to incomplete statistics, reached 137 million, which increased by $13.7 \%$ than last year. As you can see, our country's car ownership has maintained a rapid development momentum. Its reason is mainly because 2013 China's urban residents per capita disposable income reached 26955 Yuan, which made our country's households have stronger family car purchase intention. On the other hand, China's auto imports tariff cut for years, which makes the price of cars in our country also show a tendency of general decline. In addition, our country released automobile industry development support policies, which greatly improved automobile consumption environment. In order to make car have good running status and features so as to extend car service life, automobile repair industry with service properties has unprecedented development space with China's car ownership maintaining a sustained growth situation.

B. Automobile repair object owns higher level of science and technology.

After so many years of automobile industry development, current cars are made up with sensors and computers. The corresponding reliability, economy, comfort, safety, performance and so on are all under intelligent control with effective combines of high technological integrations such as new material technology, hydraulic servo drive technology, electronic technology, digital communication technology, optical fiber transmission technology, and computer network control technology. For example, in luxury cars, more than half of vehicle cost is on electronic products. Electronic gasoline injection system, electronic brake-force distribution system technology, drive torque, electronic anti-lock braking control system, electronic control automatic transmission and fault self-diagnosis system technology are widely used in these cars. The last two years, the integration of machine, electricity, liquid and whole vehicle all functions computer control has been achieved. There is an effective integration of modern high-tech. Without whole understanding of the entire car, simply with 
the help of previous traditional touch, see and listen it is hard to make accurate, fast, safe judgment of the car trouble. With modern automobile more stringent performance requirements and service standards, previous traditional test equipment and methods cannot meet the need of repair, and traditional repair technology is facing very serious challenges.

C. There is growing competition between car maintenance enterprises.

With a gusher in car ownership, large automobile repair market appears full of temptation. In the market, from the point of internal environment, our country's related vehicle maintenance enterprises increase capital investment in order to survive and develop. Other industry enterprises turn to the market, hoping get a piece of the pie. From the point of external environment, according to the relevant provisions of WTO, foreign enterprises entering our country automobile service market can adopt the way of wholly owned which not only can enjoy national treatment, also apply their modern maintenance technology, good operation mechanism and advanced management method. Foreign enterprises occupy good positions in market competition. Due to intense internal and external environment, China's automobile service market presents a more intense competition.

\section{China's Automobile Service Market Development Trend Analysis}

\section{A. Based on maintenance technology}

The first is to adopt lots of advanced diagnostic equipment for maintenance. Generally, the diagnosis here is an inspection method which under the technology condition of not knowing disassembly inspection, find out the reasons and positions of the failures. Different methods in diagnosis may direct influence automobile service life, performance and timely maintenance. Increase additional project to vehicle maintenance, which judges maintenance quality evaluation and has absolute right to implement diagnosis. For more stringent vehicle inspection standards, increased day by day test items and more high-tech cars, advanced diagnostic equipment are inevitable requirement for the Time development, and traditional diagnosis way cannot satisfy the objective needs. A relatively low level of maintenance equipment and staff craftsmanship are major means of getting maintenance tasks completed. This way of maintenance is only grasped by a small number of people with rich experience. This way is very difficult to improve and expand the scale of production efficiency, and can't meet the majority owners' timeliness. On the other hand, modern cars have higher maintenance requirements on every performance index. To ensure meeting the requirements of indicators, the low grade of service and experience seems to be more difficult. In the background, there are more and more modern maintenance equipment, such as computer color, body shaping equipment, automation equipment of lacquer bake, etc.

The second is network maintenance information. Through the analysis of modern car, more and more new function, new equipment and new brand may also bring all kinds of corresponding car troubles. Any maintenance personnel cannot store in his brain so complicated maintenance data and information, which makes it unrealistic to accurately and fast judge faults. To solve this problem, the Internet can help to establish special vehicle maintenance and repair information platform. Through the introduction of Internet technology, we can effectively break the limitation of time and space in information, which can implement the most rapid and comprehensive information with no geographical and time restrictions. On the whole, vehicle maintenance and repair network information service in China is still at the early stage. There is a huge development space for maintenance information services by network technology.

The last is moving repair focus to maintenance without disassembly and change parts. Because car repairs are the most in today's maintenance market with relatively more special types, the general owners' strong desire is the fast repair. Traditional repair method shows inadaptability. The repair focus is transferred to quick fix the part. Now quite a number of enterprises still use the traditional maintenance operation of disassembly, cleaning, inspection, and adjustment to eliminate the hidden trouble. The biggest disadvantage of the traditional maintenance operation way is that only by disassembly can it be able to determine whether there is a hidden trouble. This way is far behind the modern requirements. Automotive maintenance development trend establishes regular testing and maintenance as the basic principle of new maintenance system. This system is based on sophisticated 
diagnostic techniques without disassembly, which can save a lot of manpower, material and financial resources and can greatly reduce maintenance time accordingly.

B. Based on business model

One is networking and computerized maintenance management means. Artificial management is the main way of management in traditional vehicle maintenance enterprises. In the process of data statistics, it is relatively prone to errors, and it has low efficiency. Under the background of gradual popularization and application of computer, the use of computer management can effectively shorten the waiting time, maximally reduce management cost and improve work efficiency. With modern networked and computerized management, the production and operation management level of vehicle maintenance and repair enterprises in China will be strongly promoted.

Second, actively advocate enterprise culture, effective strengthen quality management, and establish brand awareness. The key to improving the quality of vehicle maintenance and repair is to strengthen management of vehicle maintenance and repair quality. From the reality, there is weak consciousness of quality management in vehicle maintenance enterprise in our country for a long time. With current gradually in-depth China's reform and opening up, foreign related auto service enterprises make full use of their advantages of talents; capital, information, equipment, and advanced production management concept have a certain advantage in the competition with our country's vehicle maintenance enterprise. If domestic companies can't find their own weaknesses, and strengthen and make them up, in the future they will be difficult to adapt to market competition. After strengthening the corresponding quality management, lead enterprises to develop towards a higher level, actively advocate corporate culture and establish brand awareness. To sustainable development, enterprises should have ideal corporate culture. Brand embodies the value of corporate culture, and current domestic and international numerous entrepreneurs believe that brand is the core competitiveness. From this level, vehicle maintenance and repair trend of current our country enterprise in the market is the transition from traditional maintenance quality and price competition to brand and enterprise culture.

Third is miniaturization scale. We've learned through the analysis of enterprise service market that enterprises in the market have convenience maintenance services and a wide service, which makes vehicle maintenance enterprises have decentralized operation characteristics. Market concentration decides enterprise size, and repair enterprises are similar to the dispersion characteristics of maintenance. The development direction of automobile service market is miniaturization. In terms of profitability, small companies tend to have larger advantages with more broad development space. Specifically, enterprise miniaturization is not to say that automobile maintenance is poorly equipped or with low personnel quality. The successful implementation of miniaturization business model is specialty stores. Auto specialty store only specialize in certain model car maintenance or are specific to one brand car repair. This makes maintenance personnel have stronger professional and technical level, high utilization rate of equipment. With advanced equipment and detailed and specific repair data, convenience for management is provided. Auto specialty store has faster speed of maintenance, and general car owners like the miniaturization specialize in the shop more and more.

Fourth is chaining operation mode. Due to the dispersion features of automobile service market, it is very suitable for chain operation. Chaining operation mode tends to have an economic cooperation relationship existing between headquarters and each chain. Headquarters train personnel, input devices, technology service and management to provide a comprehensive range of chain support. Standardized operation has its salient features. This way can reduce repair cost, improve maintenance speed, expand market share, reduce operating costs, standardize market behavior, and optimize enterprise resource configuration. Modern vehicle maintenance and repair chain operation is the inevitable developing trend of automobile service market. This promising business model has low cost, fast expansion, unique image, wide area and scale, etc. Although from the reality, the current our country's automobile service market chain management belongs to the start-up stage, it inevitably shows a tendency of rapid growth in the gradual development of automobile service market. 


\section{Conclusion}

To sum up, the current our country's automobile service market presents increasing competition trend. Enterprises in the market are facing unprecedented opportunities and challenges. Only by recognizing the future market development trend may the enterprises formulate realistic development strategy, and survive and develop in fierce market competition.

\section{References}

[1] He Shaotao, Jiang Guofu. Management and development of automobile maintenance industry [J]. Journal of Private Science and Technology. 2011 (3) : 211-214

[2] Xiong Yi. Car maintenance industry's present situation and countermeasure research [J]. China's New Technology and New Products. 2010 (02) : 120-121

[3] A Ergen. Ke YiMu. China's auto maintenance industry’s current situation and development trend [J]. Journal of Xinjiang Vocational University. 2008 (01) : 78-80 